\title{
Work-Family Conflict, Emotional Intelligence, and General Self-Efficacy Among Medical Practitioners During the COVID-19 Pandemic
}

\author{
Sadaf Zeb' \\ Ahsan Akbar (D) ${ }^{2,3}$ \\ Azeem Gul $\mathbb{I D}^{4}$ \\ Syed Arslan Haider ${ }^{5}$ \\ Petra Poulova (D) $^{3}$ \\ Fakhra Yasmin (1D ${ }^{6}$ \\ 'Department of Professional Psychology, \\ Bahria University, Islamabad, Pakistan; \\ ${ }^{2}$ International Business School, \\ Guangzhou City University of \\ Technology, Guangzhou, 510080, People's \\ Republic of China; ${ }^{3}$ Department of \\ Informatics and Quantitative Methods, \\ Faculty of Informatics and Management, \\ University of Hradec Kralove, Hradec \\ Kralove, 500 03, Czech Republic; \\ ${ }^{4}$ Department of International Relations, \\ National University of Modern \\ Languages, Islamabad, 45320, Pakistan; \\ ${ }^{5}$ Department of Management, Sunway \\ University, Selangor Darul Ehsan, 47500, \\ Malaysia; ${ }^{6}$ School of Education, South \\ China Normal University, Guangzhou, \\ 5I063I, People's Republic of China
}

Purpose: In Pakistan, medical professionals face multiple challenges comprising long, fixed working hours and workload overburdening, which leads to emotional fatigue. These conflicts in work-life scenarios, brought about by high work demands causing emotional exhaustion, can create a state of distress among the medical professionals. The present study investigates the association between work-family conflict (WFC), emotional intelligence (EI), and self-efficacy (SE) among medical practitioners during COVID-19 in Pakistan.

Patients and Methods: The study sample included 140 medical professionals from Rawalpindi and Islamabad. Cross-section correlational research design was used, and information was gathered employing online surveys through a purposive sampling technique. The scales utilized were the WFC, EI, and SE Scale.

Results: The current study hypothesized a significant relationship between work-family conflict, general self-efficacy (GSE) and emotional intelligence among medical practitioners during COVID-19 in Pakistan. The results showed that those with more family-to-work conflict had less EI and GSE. Furthermore, findings uncovered that there is a significant positive relationship between EI and GSE.

Conclusion: The findings propose that it is important for medical professionals to have a high level of EI and GSE to navigate through the WFC more healthily. In future, awareness seminars could be arranged related to EI and its significance to stimulate the psychological well-being of medical professionals. Future studies could also consider other healthcare workers, including nurses and internees doing house jobs and other medical staff, as they are also exposed to several stresses due to the workload and family demands.

Keywords: emotional fatigue, purposive sampling, medical professionals, work-life balance

\section{Introduction}

The Epidemic of Coronavirus disease (COVID-19) is viewed as an overall wellbeing peril, a worldwide health hazard, becoming the third significant coronavirus outbreak in recent times following severe acute respiratory syndrome (SARS) and the Middle East respiratory syndrome (MERS). Difficulties related to the COVID19 pandemic (eg, substantial responsibility, work pressure, serious danger of disease, lacking assets) may affect the mental health of healthcare personnel, for example, forefront employees, principally as far as their burnout degree. ${ }^{3}$ The flareup of another COVID infection, COVID-19, has been pronounced to be a Public Health Emergency of International Concern and described as a pandemic
Correspondence: Ahsan Akbar;

Fakhra Yasmin

Tel +86 I3802400964

Email akbar@gcu.edu.cn; fakhra.

yasmin@hotmail.com 
throughout the world (WHO, January 2020). COVID-19 has influenced 199 nations, including Pakistan, up until now with the principal episode of the pandemic in Wuhan, China. COVID sickness (COVID-19) is an irresistible infection that causes respiratory disease (similar to influenza) with symptoms including a cough, fever, sore throat, nausea, heaving, looseness of the bowels, and in more extreme cases, trouble breathing. As per the guidelines of WHO, the preventive measures and policies that the nations have adopted to curtail the spread of epidemics, such as social seclusion, remaining at home, the total closure of schools, colleges, universities, and other workplaces, appear to adversely affect the mental well-being of people of all age groups.

The medical profession is characterized by high demands in both physical and emotional aspects. Medical professionals encounter multiple challenges comprising long and inflexible work hours, workload overstraining leading to emotional fatigue. Emotional fatigue is a key response to the work overload, ie, high job demands that they are exposed to. A study by Greenglass, Burke, and Fiksenbaum in 2001 confirmed the association of workload with emotional fatigue in hospital nurses. ${ }^{8}$ In return, this emotional exhaustion negatively affects employee's self-efficacy level hence weakens an organization's ability to achieve its objectives. Due to high work demands, work-life conflicts are caused leading to emotional exhaustion, which creates a state of distress among the medical professionals. This stress can be easily controlled if their emotional intelligence levels are high; various studies have confirmed that high levels of emotional intelligence are linked with lower levels of stress in the workplace since emotional intelligence helps improve one's performance by easing the negative effect of stress. ${ }^{5}$

WFC is a two-way conflict that comprises both WFC and FWC. ${ }^{9,19,25}$ WFC is a type of inter-role conflict where the general requirements, time devoted to, and pressure made by the work meddle with performing family-related responsibilities. FWC is a type of inter-role conflict where the overall demands, time committed to, and strain created by family meddle with taking care of job-related obligations. ${ }^{10}$ Medical professionals have to adjust to every family event, despite having long working hours, overnight calls, and duties. Daily working routine and long duty hours at weekends mean that family time is not compensated and is unlikely to recover. Furthermore, sleep deprivation makes the doctors more irritable and illtempered at home, which affects their family life. Due to these factors, they must alleviate the conflict between work and family. Mental and emotional fatigue increases in doctors after working round the clock, this affects their mood, and they also neglect their family life. In Pakistan, due to the presence of fewer doctors, they sometimes have to work for more than 24 hours, and this causes them to question their priorities because, due to this, they are not able to maintain a balance between their long and stressful hours of working and their family life. Along with their working load, they also have to study and continuously update their knowledge and requirements. Living under continuous stress and dissatisfaction with their family and work-life leads doctors towards burnout, depression, isolation, family problems, and divorce. ${ }^{26}$

The medical healthcare workers exposed to, and in contact with, all the confirmed and suspected coronavirus cases are vulnerable to both high-hazard issues and psychological well-being issues, such as stress, terror, grief and trauma ${ }^{11}$ With the onset of COVID-19 in Pakistan, healthcare workers have been under physical and mental pressure, including a higher risk of sickness, inadequate equipment for safety from contagion, confinement, fatigue, and absence of contact with family. The seriousness of the situation is bringing on additional psychological wellness issues that influence medical employees' decision-making ability and may also have long-term harmful impacts on their overall well-being. The ongoing pressure that clinical medical services workers are encountering can trigger emotional issues of stress, anxiety, panic attacks, posttraumatic stress manifestations, psychological distress, stigma and aversion to contact, depressive tendencies, sleep disturbances, vulnerability, social disengagement from family social support, and stress concerning vulnerability to the virus in their loved ones.

The abrupt role inversion from a medical services supplier to the COVID-19 affirmed or suspected patients perhaps adds to a feeling of frustration, defenselessness, and adjustment challenges in medical care workers. ${ }^{21} \mathrm{~A}$ study was done by Peter, Rima, and Wayne in 2020 on healthcare professionals during the Covid-19 period. The results show that the physicians dealing with the patients directly had more depression, distress, anxiety, and insomnia. Furthermore, the healthcare staff who were receiving high social support had less anxiety and stress, and more self-efficacy was seen in them. A survey was performed on 6000 doctors during the COVID-19 outbreak. The survey results showed that $44 \%$ of doctors were experiencing anxiety, depression, stress, burnout, and other mental health problems due to which their 
work and duties became difficult for them. ${ }^{2}$ According to the role theory by Katz and Kahn in 1978, there is a difficulty in meeting the demands of both roles, demands from behavior, time and strain in family and work, resulting in WFC. ${ }^{9}$

The conflict of not performing according to the demands and requirements of the role occurs in two directions: one is from Family-Work, and the other is from Work-Family life. ${ }^{4}$ At the point when time is requested in family and work-life, while both are competing with each other at that point, time-sensitive role conflict occurs. When an individual experiences issues playing out in one role, while having strain in another role, this brings about strain-based conflict. Therefore, behavior-based conflict occurs when behavior norms identified with family and work are not compatible., ${ }^{9,13,26}$

A recent study was performed in which the focal point of the investigation was the way the emotional well-being of medical services workers was influenced during the COVID-19. The relationship was identified between sociodemographic, COVID-19 related stress, and psychological variables, such as self-efficacy, sleep quality, nervousness, and stress among medical services workers. The results showed that healthcare workers encountered stress, anxiety, lack of sleep, depression, and a decline in self-efficacy due to COVID-19. ${ }^{17}$ A study was done on 194 doctors, comprising $60 \%$ females and $2.97 \%$ who worked with COVID-19 patients, to recognize the mental well-being of doctors during the COVID-19 episode in Oman. The results obtained showed that married physicians had lower stress levels than unmarried physicians, whilst females were experiencing more stress than males. ${ }^{1}$

A study highlighted those medical professionals' experience, which raised degrees of work pressure fundamentally under common conditions. However, most of the employees would be hesitant to reveal emotional wellness challenges or search for help with reluctance. The Covid-19 crisis puts an additional load on subject matter experts and the human administration system at the end of the day. ${ }^{15}$ Research shows that such weight brings more risk of mental suffering among medical professionals. ${ }^{6}$ Furthermore, past examination additionally inferred that mindfulness, self-management, perspective taking, searching for input, self-awareness, dependability, taking care of strife, building associations, learning agility, and authoritative comprehension are the significant emotional intelligence factors among healthcare professionals dealing with the COVID-19 pandemic for effective relationship management. ${ }^{18}$
The significance of the study is to discover the impact of WFC on SE and EI among medical practitioners during COVID-19 in Pakistan. In a country like Pakistan, many medical practitioners working in government and private sectors are going through work-family conflict because of increased hours of work, long duties, night shifts, and busy schedules. Due to this, doctors are sometimes not capable of administering a balance between their family and work, which brings about many conflicts in their life. This affects their self-efficacy, which is the achievement of their proper goals, and also has an impact on their emotional intelligence, which results in their poor performance. This would affect their patient handling skills. It is also a general assumption that many individuals working as medical practitioners are going through an imbalance between their family and work life, making it challenging for them to cope with stress and personal pressure. A doctor with high EI can meet the needs of their patients and provide them with better care, which will result in patient satisfaction. Limited research has been published in the Association of WFC, EI, and SE among a sample of doctors in Pakistan. Therefore, the aim of this research is to explore the relationship between WFC, SE, and EI among medical practitioners. Moreover, to find out the effect of WFC on emotional intelligence and general selfefficacy among medical practitioners.

\section{Materials and Methods}

\section{Hypotheses}

1. There would be a significant relationship between WFC and EI among medical practitioners.

2. There would be a significant relationship between WFC and general self-efficacy among medical practitioners.

3. There would be a significant relationship between EI and GSE among medical practitioners.

4. There would be a significant effect of WFC on EI and GSE among medical practitioners.

\section{Research Design}

In the present study, a cross-sectional correlation design study was used.

\section{Subjects}

The participants were chosen through a purposive sampling technique. G calculated the sample size of the present research- power, ie 140 doctors, which was taken 
from different government, semi-government and private hospitals. This study involved all the doctors who were presently working in different hospitals and clinics. There were no restrictions on age, department or socioeconomic status. In the present study, unemployed doctors were not included. To collect data for the current study, the heads of different institutions were contacted for permission. Then, doctors from different hospitals, including government, private and semi-government, were approached. Due to the current condition in the world due to the spread of coronavirus, many of the doctors were approached through online forms. Informed consent was taken, and confidentiality of the information was assured. Demographic sheets and three questionnaires of WFC, EI, and GSE were provided to them to collect data. The participants were assisted with any difficulties they faced.

\section{Instruments}

\section{Demographic Sheet}

The demographic sheet includes gender, age, marital status, family members, family system, number of children, father and mother alive or deceased, birth order, earning members of the family, designation, qualification, specialization, tenure of working, sector of the workplace, duration of the job and monthly income.

\section{Work and Family Conflict Scale (Netemeyer, Boles \& McMurrian, 1996)}

The WFC scale was used to find the WFC and FWC in medical professionals in the current study. The developers of this scale were Netemeyer, Boles, and McMurrian in 1996. ${ }^{19}$ It consists of 10 items assessing WFC (five items) and FWC (five items). It is marked on a 7-point Likert scale ranging from very strongly agree (5) to very strongly disagree (1). Items are totalled for each subscale to give the total scores of WFC (ranging from 7 to 35) and FWC score (ranging from 7 to 35); higher levels of conflict are indicated by the higher scores obtained. Overall, Cronbach's alpha was 0.88 .

\section{Emotional Intelligence Scale (Wong \& Law, 2002)}

The response of Wong and Law emotional intelligence scale (WLEIS) is marked on a seven-point Likert scale $(0=$ disagree to $6=$ agree). Wong and Law, in 2002, were its developers, and this scale was used to assess EI. ${ }^{20}$ It consists of four subscales and 16 numbered items, with four items each: SEA, OEA, ROE, and UOE. To give a total score, all the scores for every 16 items are added up. For the four subscales, the WLEIS showed good internal consistency reliability. Overall Cronbach's alpha was 0.88 .

\section{General Self-Efficacy Scale (Jerusalem \& Schwarzer, 2010)}

The GSE scale is used to measure the SE among doctors. Jerusalem and Schwarzer developed the scale in 2010. It consists of 10 items, marked on a four-choice response from "Not at all true" which scores 1 to "Exactly true" which scores 4 . The total scores are given by summing up all the scores for each of the ten items. ${ }^{21}$ Overall, Cronbach's alpha for the scale was 0.88 .

\section{Procedure}

To collect data for the current study, the heads of different institutions were contacted for permission. Then, doctors from different hospitals, including government, private, and semi-government, were approached. Due to the current condition in the world due to the spread of coronavirus, many of the doctors were approached through online forms. Informed consent was taken, and confidentiality of the information was assured. Demographic sheets and three questionnaires of WFC, EI, and GSE were provided to them to collect data. The participants were assisted with any difficulties they faced. The study was approved by the Institutional Review Board of the first author's institution.

\section{Ethical Considerations}

Consent was taken because personal information was obtained from the participants for the study. The objective of this research was informed to the individuals that participated, and they were also informed about the confidentiality of the information they were providing. The participants were also informed that they could leave the study whenever they felt uncomfortable answering any questions asked in the questionnaire.

\section{Data Analysis}

The SPSS software (version 25) was used to analyze the present study's data. Descriptive characteristics, mean reliability, standard deviation, and range were assessed for all the study variables. Pearson bivariate correlation and regression analysis was used to analyze the study variables.

\section{Results}

Table 1 reports the basic descriptive statistics among the study variables. The sample consisted of 140 participants. 
As shown in the table, participants in the age range of 28 30 comprised $62(44.3 \%), 31-40$ comprised 34 (41.1\%), 41-50 comprised of 10 (7.1\%), 52-60 comprised 15 (10.7\%), above 60 comprised $9(6.4 \%) .81(57.9 \%)$ of the participants were married, while 59 (42.1\%) were unmarried. From the members of participants 109 (77.9\%) were medical officers, $1(0.7 \%)$ was an ophthalmologist, 4 (2.9\%) were pharmacists, 5 (3.6\%) were dentists, $5(3.6 \%)$ were senior registrars, $6(4.3 \%)$ were physiotherapists, $3(2.1 \%)$ were anesthetists, $2(1.4 \%)$ were coordinators, $2(1.4 \%)$ were neurologists and 3 $(2.1 \%)$ were cardiologists. 56 (40.05) were working in the government sector, $23(16.4 \%)$ were in the semigovernment sector, and 61 (43.65) were working in the private sector. $98(70.0 \%)$ were working in the range from 5 to 8 hours, 33 (23.6\%) were working in the range from 9 to 32 hours, and $9(6.4 \%)$ were working in more than 32 hours. The employment of $75(53.6 \%)$ participants was permanent, and 65 (46.4\%) was temporary. Categories of all demographics are comprehensively described in Table 1.

Alpha reliability of the scales and subscales were assessed. Three scales were used, ie WFC scale, ${ }^{19}$ EI scale,$^{20}$ and GSE scale. ${ }^{21}$ The alpha reliability of the EI subscales was 0.87 for self-emotion appraisal, 0.90 for others' emotional appraisal, 0.87 for regulation of emotion, and 0.91 for the use of emotion. Subscales of work and family conflict scales (WAFCS) showed that Workfamily conflict had an alpha reliability of 0.89 , and the FWC had 0.90 . The alpha reliability of the GSE was 0.86 .

A correlational analysis was utilized to calculate the relationship between EI, WAFCS, and SE among medical practitioners. The table revealed that the FWC subscale has a significant negative relationship with the SEA subscale, ROE subscale, OEA subscale, EI, and SE. It means that those having more FWC were having less EI and SE. SEA, UOE and OEA subscales have a significant positive relationship with SE, meaning those with more emotional intelligence tend to have more self-efficacy. EI shows a significantly positive relationship with SE $(r=0.60)$ and a significant negative relationship with WAFCS $(\mathrm{r}=$ 0.29). SE shows a significant negative relationship with WAFCS.

Table 2 shows a regression model predicting emotional intelligence among medical practitioners. It shows that with every one-unit change in the FWC, the selfemotions appraisal subscale will decrease by 0.07 units.
Table I Frequencies and Percentages of the Demographic Characteristics of Sample $(N=\mid 40)$

\begin{tabular}{|c|c|c|c|}
\hline Variables & & f & $\%$ \\
\hline \multirow[t]{5}{*}{ Age } & $28-30$ & 62 & 44.3 \\
\hline & $31-40$ & 44 & 31.4 \\
\hline & $4 I-50$ & 10 & 7.1 \\
\hline & $51-60$ & 15 & 10.7 \\
\hline & Above 60 & 9 & 6.4 \\
\hline \multirow[t]{2}{*}{ Gender } & Male & 65 & 46.4 \\
\hline & Female & 75 & 53.6 \\
\hline \multirow[t]{2}{*}{ Marital Status } & Married & 81 & 57.9 \\
\hline & Unmarried & 59 & 42.1 \\
\hline \multirow[t]{3}{*}{ Family Members } & $2-5$ & 45 & 32.1 \\
\hline & $6-9$ & 71 & 50.7 \\
\hline & $10-15$ & 24 & I7.1 \\
\hline \multirow[t]{6}{*}{ No of Children } & 0 & 57 & 40.7 \\
\hline & I & 22 & 15.7 \\
\hline & 2 & 29 & 20.7 \\
\hline & 3 & 22 & 15.7 \\
\hline & 4 & 6 & 4.3 \\
\hline & 5 & 4 & 2.9 \\
\hline \multirow[t]{2}{*}{ Family System } & Joint & 71 & 50.7 \\
\hline & Nuclear & 69 & 49.3 \\
\hline \multirow[t]{6}{*}{ Birth order } & I & 51 & 36.4 \\
\hline & 2 & 44 & 31.4 \\
\hline & 3 & 18 & 12.9 \\
\hline & 4 & 24 & I7.I \\
\hline & 5 & 2 & 1.4 \\
\hline & 6 & 1 & 0.7 \\
\hline \multirow[t]{6}{*}{ Earning Members } & I & 29 & 20.7 \\
\hline & 2 & 53 & 37.9 \\
\hline & 3 & 39 & 27.9 \\
\hline & 4 & 10 & 7.1 \\
\hline & 5 & 6 & 4.3 \\
\hline & 6 & 3 & 2.1 \\
\hline \multirow[t]{6}{*}{ Designation } & Medical officer & 106 & 75.7 \\
\hline & Ophthalmologist & I & 0.7 \\
\hline & Dentist & 17 & 12.1 \\
\hline & Anesthetist & 5 & 3.6 \\
\hline & Cardiologist & 5 & 3.6 \\
\hline & Neurologist & 6 & 4.3 \\
\hline \multirow[t]{2}{*}{ Qualification } & MBBs & 123 & 87.9 \\
\hline & BDs & 17 & 12.1 \\
\hline \multirow[t]{5}{*}{ Tenure } & Less than I year & 24 & 17.1 \\
\hline & $\mathrm{I}-3$ year & 42 & 30 \\
\hline & 4-6 year & 26 & 18.6 \\
\hline & $7-10$ year & 18 & 12.9 \\
\hline & More than 10 year & 30 & 21.4 \\
\hline
\end{tabular}

(Continued) 
Table I (Continued).

\begin{tabular}{|l|l|c|c|}
\hline Variables & & f & $\%$ \\
\hline Workplace sector & Government & 56 & 40 \\
& Semi government & 23 & 16.4 \\
& Private & 61 & 43.6 \\
\hline Average hour of & $5-8$ & 98 & 70 \\
working & $9-32$ & 33 & 23.6 \\
& More than 32 & 9 & 6.4 \\
\hline Type of employment & Permanent & 75 & 53.6 \\
& Temporary & 65 & 46.4 \\
\hline Monthly Income & $19,000-73,000$ & 65 & 46.4 \\
& $73,000-150,000$ & 46 & 32.9 \\
& $150,000-$ & 29 & 20.7 \\
& $10,000,000$ & & \\
\hline
\end{tabular}

This suggests that this model accounts for an $11 \%$ change in the variance of the self-emotion appraisal subscale of emotional intelligence. The findings also indicate that with every one-unit change in FWC, the regulation of emotions, use of emotions and other emotions appraisal will decrease by $0.05,0.06$, and 0.08 units, respectively. This suggests that this model accounts for a $9 \%, 9 \%$, and $12 \%$ change in the variance of the regulation of emotions, use of emotions and other emotion appraisal subscales of emotional intelligence.

Table 3 shows a regression model predicting general self-efficacy among medical practitioners. It shows that with every one-unit change in the FWC the general selfefficacy will decrease by 0.38 units. This suggests that this model accounts for an $18 \%$ change in the variance of the general self-efficacy scale.

\section{Discussion}

The present study aimed to find the association of WFC, EI, and self-efficacy among medical professionals during
COVID-19. Developing emotional intelligence in medical workers is essential for lowering chronic stress. ${ }^{22}$ Emotional intelligence can help prevent the burnout syndrome among healthcare workers. Hence, devising stress coping strategies and improving emotional intelligence can enhance mental well-being and prevent work-related mental disorders. The participants included 140 medical professionals working in private, government, and semigovernment hospitals. The COVID-19 pandemic has, unfortunately, placed medical professionals all over the world in exceptional circumstances, facing incomprehensible choices and working under extreme pressures. These choices may incorporate how to apportion meagre assets to similarly penniless patients, how to adjust their own physical and mental health needs with those of their patients, how to adjust their devotion and obligation to patients with those to loved ones, and how to give care to all seriously unwell patients with compromised or insufficient assets. This may cause some to experience moral injury or emotional well-being issues. ${ }^{7}$ Three scales were used, ie WFC scale, developed by Netemeyer, Boles and McMurrian, in 1996, EI scale by Wong and Law in 2002, and GSE scale by Jerusalem and Schwarzer in 2010. The WFC scale consists of 10 items assessing WFC (five items) and FWC (five items). The GSE scale consists of 10 items to assess optimistic self-beliefs to cope with a variety of difficult demands in life. The EI scale is used to measure the level of emotional intelligence. It consists of 16 items and four subscales, with four items each: SEA, OEA, ROE, and UOE. The alpha reliability of the EI subscales was 0.87 for self-emotion appraisal, 0.90 for other emotional appraisals, 0.87 for regulation of emotion, and 0.91 for the use of emotion. Subscales of WAFCS showed that Work-family conflict had an alpha reliability of 0.89 , and family-to-work conflict had 0.90 (Table 4).

Table 2 Regression Model of Work-Family Conflict Predicting Emotional Intelligence Among Medical Practitioners

\begin{tabular}{|c|c|c|c|c|c|c|c|c|c|c|c|c|}
\hline \multirow[t]{2}{*}{ Predictors } & \multicolumn{3}{|c|}{ Self-Emotions Appraisal } & \multicolumn{3}{|c|}{ Regulation of Emotions } & \multicolumn{3}{|c|}{ Use of Emotions } & \multicolumn{3}{|c|}{ Others Emotion Appraisal } \\
\hline & B & SE & $95 \% \mathrm{Cl}$ & B & SE & $95 \%$ & B & SE & $95 \% \mathrm{Cl}$ & B & SE & $95 \% \mathrm{Cl}$ \\
\hline Constant & $5.52^{* *}$ & 0.27 & $4.99,6.06$ & $5.60 * *$ & 0.24 & $5.13,6.07$ & $6.11 * *$ & 0.27 & $5.58,6.65$ & $5.47 * *$ & 0.31 & $4.86,6.08$ \\
\hline WFC & 0.41 & 0.02 & $0.01,0.07$ & 0.04 & 0.01 & $0.01,0.06$ & 0.22 & 0.15 & $-0.01,0.05$ & 0.03 & 0.17 & $-0.003,0.07$ \\
\hline FWC & $-0.07 * *$ & 0.02 & $-0.10,-0.04$ & $-0.05^{*}$ & 0.02 & $-0.08,-0.02$ & $-0.06 * *$ & 0.17 & $-0.09,-0.03$ & $-0.08 * *$ & 0.02 & $-0.12,-0.04$ \\
\hline$R^{2} / R^{2}$ adjusted & $0.11 / 0.09$ & & & \multicolumn{3}{|c|}{$0.09 / 0.07$} & $0.09 / 0.08$ & & & $0.12 / 0.11$ & & \\
\hline
\end{tabular}

Note: ${ }^{*} p<0.05,{ }^{*}{ }_{p}<0.01$. 
Table 3 Regression Model of Work-Family Conflict Predicting Emotional Intelligence Among Medical Practitioners

\begin{tabular}{|l|c|c|c|}
\hline \multirow{2}{*}{ Predictors } & \multicolumn{3}{|c|}{ GSE } \\
\cline { 2 - 4 } & B & SE & $95 \%$ Cl \\
\hline Constant & $34.15^{* *}$ & 1.14 & $31.89,36.41$ \\
WFC & 0.11 & 0.06 & $-0.02,0.24$ \\
FWC & $-0.38^{* *}$ & 0.07 & $-0.53,-.24$ \\
$\mathrm{R}^{2} / \mathrm{R}^{2}$ adjusted & $0.18 / 0.17$ & & \\
\hline
\end{tabular}

According to the first hypothesis, there is a significant negative relationship between WFC and EI among medical practitioners. This is supported according to the current study's findings, which revealed that the FWC subscale has a significant negative relationship with the SEA subscale, ROE subscale, OEA subscale, and UOE subscale of emotional intelligence (Table 5). It showed that those with more FWC had less EI. Previous literature also shows a significant relationship between EI and WFC, particularly in self-management, social awareness, and relationship management. ${ }^{23}$ Results from Lenaghan et al 2007 also showed that the lowest well-being is reported when there is a high level of WFC and a low level of emotional intelligence. ${ }^{14}$

Secondly, there is a significant negative relationship between WFC and SE among medical practitioners. Our study revealed a significant negative relationship between WFC and SE, which supported our hypothesis (Table 5). Greenhaus and Beutell in 1985 showed that work-family conflict heightens when family or work roles are essential to one's self-concept. ${ }^{9}$ A high level of self-efficacy is needed to manage the conflict between work and family.

Table 4 Psychometric Properties of Study Variables $(\mathrm{N}=\mid 40)$

\begin{tabular}{|l|c|c|c|c|c|}
\hline \multirow{2}{*}{ Scale } & \multirow{2}{*}{ M } & \multirow{2}{*}{ SD } & \multicolumn{2}{|c|}{ Range } & \multirow{2}{*}{ Cronbach $\alpha$} \\
\cline { 4 - 5 } & & & Min & Max & \\
\hline SE & 31.19 & 5.28 & 18 & 40 & 0.86 \\
WAFCS & 33.49 & 13.15 & 10 & 65 & 0.91 \\
EI & 5.42 & 0.95 & 29 & 112 & 0.92 \\
SEA & 5.40 & 1.19 & 2 & 7 & 0.87 \\
OEA & 4.96 & 1.38 & 1 & 7 & 0.90 \\
ROE & 5.60 & 1.03 & 2 & 7 & 0.87 \\
UOE & 5.70 & 1.18 & 1 & 7 & 0.91 \\
WFC & 20.05 & 7.87 & 5 & 35 & 0.89 \\
FWC & 13.43 & 6.88 & 5 & 31 & 0.90 \\
\hline
\end{tabular}

Abbreviations: $M$, mean; SD, standard deviation; WFC, work family conflict; FWC, family work conflict; SE, self-efficacy; El, emotional intelligence; WAFC, work and family conflict scale; SEA, self-emotion appraisal; OEA, others emotional appraisal; ROE, regulation of emotion; UOE, use of emotion.
Results indicated an inverse relationship between WFC and SE. Furthermore, WFC and FWC have a significant negative relation to all the factors of job-related selfefficacy. ${ }^{12}$ The third hypothesis was that there is a significant positive relationship between EI and SE among medical practitioners. This hypothesis was also supported according to the present research findings, which showed that EI has a significant positive relationship with SE, which means those with more emotional intelligence have more self-efficacy (Table 5). A prevailing consensus supports our results about a significant positive relationship between EI and SE. ${ }^{24}$ Rastegar and Memarpour in 2009 also revealed a significant positive correlation between perceived EI and self-efficacy. ${ }^{25}$

Moreover, according to the fourth hypothesis, WFC predicts EI and GSE among medical practitioners. Previous studies demonstrated that physicians who reveal elevated levels of self-efficacy, resilient coping behavior and optimism might be more effective at preventing WFC. These doctors seem prone to having the ability to comprehend what parts job function and household play in these areas and also have a greater insight into planning how family and job demands can be handled. In the example of managing conflicts between work and private duties, selfefficacy and resilient coping behavior could offer a view on what may ultimately help reduce negative impacts. ${ }^{26}$ Emotional intelligence is vital for the development of social and professional skills among healthcare professionals. Past analysis demonstrated an inverse relationship between work-life balance and emotional direction, motivation, and compassion. ${ }^{16}$ The study aimed to investigate the pervasiveness of fatigue among medical professionals during the pandemic examine the intervening impact of post-traumatic stress disorder, side effects, and direct impact of negative coping on the relationship between self-efficacy and fatigue. It was concluded that more than half of all medical professionals suffer from fatigue during the COVID-19. ${ }^{27}$

\section{Conclusion}

The study findings indicate that those experiencing more FWC were having less EI and GSE. Furthermore, EI shows a significant positive relationship with selfefficacy and a significant negative relationship with WFC. The sample of the study was medical professionals, ie doctors only. Future studies can also consider other healthcare workers, including nurses and other staff 
Table 5 Pearson Product Moment Correlation Among WAFCS, Self-Efficacy Scale and Emotional Intelligence Scale (N=|40)

\begin{tabular}{|c|c|c|c|c|c|c|c|c|c|c|c|c|}
\hline & & $\mathbf{M}$ & SD & I & 2 & 3 & 4 & 5 & 6 & 7 & 8 & 9 \\
\hline 1 & WFC & 20.06 & 7.88 & \multirow[t]{9}{*}{-} & \multirow{9}{*}{$\begin{array}{r}0.59 * * \\
-\end{array}$} & 0.03 & 0.06 & -0.07 & -0.06 & -0.01 & -0.13 & $0.91 * *$ \\
\hline 2 & FWC & 13.44 & 6.89 & & & $-0.24 * *$ & $-0.19 *$ & $-0.28 * *$ & $-0.31 * *$ & $-0.33^{* *}$ & $-0.40 * *$ & $0.87^{* *}$ \\
\hline 3 & SEA & 5.41 & 1.20 & & & \multirow[t]{7}{*}{-} & $0.65 * *$ & $0.46 * *$ & $0.50 * *$ & $0.8 I^{* *}$ & $0.39 * *$ & -0.11 \\
\hline 4 & ROE & 5.61 & 1.04 & & & & \multirow[t]{6}{*}{-} & $0.40 * *$ & $0.48 * *$ & $0.77^{* *}$ & $0.38 * *$ & -0.06 \\
\hline 5 & UOE & 5.70 & 1.19 & & & & & - & $0.53 * *$ & $0.76 * *$ & $0.6 I^{* *}$ & $-0.19 *$ \\
\hline 6 & OEA & 4.97 & 1.38 & & & & & & - & $0.82^{* *}$ & $0.5 \mathrm{I} * *$ & $-0.20 *$ \\
\hline 7 & EI & 5.42 & 0.95 & & & & & & & - & $0.60 * *$ & $-0.18^{*}$ \\
\hline 8 & SE & 31.19 & 5.28 & & & & & & & & - & $-0.29 * *$ \\
\hline 9 & WAFCS & 33.49 & 13.15 & & & & & & & & & - \\
\hline
\end{tabular}

Note: ${ }^{\mathrm{p}}<0.05, * *_{\mathrm{p}}<0.01$.

Abbreviations: WFC, work family conflict; FWC, family work conflict; SE, self-efficacy; El, emotional intelligence; WAFC, work and family conflict scale; SEA, self-emotion appraisal; OEA, others emotional appraisal; ROE, regulation of emotion; UOE, use of emotion.

members, as they are also exposed to several stresses due to their workload and family demands.

\section{Implications}

This research emphasizes the significance of EI and GSE and how these factors/variables help in handling stress at work and home, ie how these variables are linked and important in managing work-family conflict among medical professionals. The outcomes propose that it is significant for medical professionals to have high EI and GSE levels to navigate through the WFC in a more healthy and well-balanced way. Hence, physicians and healthcare administration should devise SOPs to ensure a healthy workplace environment. $^{28,29}$ Besides, following the practices of advanced countries, occupational health surveillance should be implemented in the workplace setting, especially to tackle the negative impact of the COVID19 pandemic. $^{30,31}$

Awareness projects or seminars could be arranged in the future related to EI and its importance in promoting the psychological well-being of medical health workers. These seminars could be advertised to encourage the doctors to attend them. Emotional intelligence awareness training should be incorporated into their curriculum. Medical institutions ought to fortify the training of the psychological skills of clinical staff. Special consideration ought to be paid to the psychological wellness of healthcare workers. The incongruence between work and family could be resolved by reducing the workload, offering a pay rise, and offering flexible working hours. Upon improvement of the work conditions, there is a possibility that the WFC could decrease and the job performance could, thus, be enhanced. Conducting health surveillance programs and seminars related to strategies of dealing with workplace stress would be effective and also prevents health issues. Additionally, social activities including sharing experiences with the family members, friends and colleagues would also help to lessen burnout among medical practitioners.

\section{Limitations of the Study}

However, our research is subject to numerous limitations. One of the most significant limitations to the generalization of these results is the insufficient sample size. As it is known, a research study with an insufficient sample size does not possess sufficient statistical power to determine meaningful effects between the variables and, therefore, may generate unreliable results that cannot be generalized to the whole population. The data was collected online via Google forms. There is a high probability that we may not even know if the people filling out the surveys are the population of interest, ie, medical professionals. There is also a possibility that the individuals who filled out the surveys might not be fully engaged or might not be providing us with the correct demographic information. The subjects may choose a more socially acceptable option rather than being honest. By considering all these possibilities, there is a slight chance that one of these scenarios could be true, which would have affected the overall reliability of our study. Lack of previous research studies could be a possible limitation since the prior writing should give hypothetical establishments to the examination question one is researching. In any case, earlier examinations that apply to our exploration subject were insufficient. Due to the current prevailing conditions caused by COVID-19 there was limited access to the respondents, ie online data collection was the only option. These drawbacks of the online data collections, as 
discussed earlier, could have affected our results. Due to the ongoing pandemic situation, time constraints, and strict deadlines, we could not collect sufficient data. Along with that, the results of our study are not reliable because of the impediments as mentioned earlier.

\section{Suggestions for Future Research}

The sample of the current research was medical professionals, ie, doctors only. For future research, it might be useful to broaden the variables used in this study, for instance, job stress, burnout due to work overload along with certain variables related to gender and personality, eg, the big five personality traits. ${ }^{32}$ Future studies in this domain can also consider other healthcare workers, including nurses and internees doing house jobs, as they are also exposed to several stresses due to their workload and family demands. Furthermore, it will be interesting to uncover the influence of COVID-19 pandemic related stress on self-efficacy and emotional well-being of workers who are engaged in project-based jobs. ${ }^{33}$ Nevertheless, future line of research can also explore the influence of lack of infrastructure and funding for the welfare of healthcare workers in developing countries on their emotional well-being. ${ }^{34-36}$

\section{Ethics Statement}

The Institutional Review Board (IRB) of the Department of Professional Psychology, Bahria University, Islamabad approved the study. The consent obtained prior to the study commencement from the study participants was "informed consent" and the guidelines outlined in the Declaration of Helsinki were followed.

\section{Funding}

The open access to this research is supported by the SPEV project 2021 at the Faculty of Informatics and Management, University of Hradec Kralove, Czech Republic.

\section{Disclosure}

The authors reported no conflicts of interest in this work.

\section{References}

1. Abdallah M, Faryal K, Nawal M. The psychological well-being of physicians during COVID-19 outbreak in Oman. J Psychiatr Res. 2020;289. doi:10.1016/j.psychres.2020.113053.
2. BMC news. Stress and burnout warning during covid19; 2020 Available from: https://www.bma.org.uk/newsand-opinion/stress-andburnout-warning-over-covid-19. Accessed October 28, 2021.

3. Cotel A, Golu F, Pantea Stoian A, et al. Predictors of burnout in healthcare workers during the COVID-19 pandemic. In: Healthcare. Vol. 9. Multidisciplinary Digital Publishing Institute; 2021:304.

4. Ernst Kossek E, Ozeki C. Work-family conflict, policies, and the joblife satisfaction relationship: a review and directions for organizational behavior-human resources research. J Appl Psychol. 1998;83 (2):139. doi:10.1037/0021-9010.83.2.139

5. Fariselli L, Ghini M, Freedman J. Age and emotional intelligence. In: Six Seconds. The Emotional Intelligence Network; 2008:1-10.

6. Galbraith N, Boyda D, McFeeters D, Hassan T. The mental health of doctors during the Covid-19 pandemic. BJ Psych Bull. 2020;1-7. doi:10.1192/bjb.2020.44

7. Greenberg N, Docherty M, Gnanapragasam S, Wessely S. Managing mental health challenges faced by healthcare workers during covid-19 pandemic. BMJ. 2020;m1211. doi:10.1136/bmj.m1211

8. Greenglass ER, Burke RJ, Fiksenbaum L. Workload and burnout in nurses. J Commun Appl Soc Psychol. 2001;11(3):211-215. doi:10.1002/casp.614

9. Greenhaus JH, Beutell NJ. Sources of conflict between work and family roles. Acad Manag Rev. 1985;10(1):76-88. doi:10.2307/258214

10. Hao J, Wu D, Liu L, Li X, Wu H. Association between work-family conflict and depressive symptoms among Chinese female nurses: the mediating and moderating role of psychological capital. Int J Environ Res Public Health. 2015;12(6):6682-6699. doi:10.3390/ijerph120606682

11. Hou T, Dong W, Zhang R, et al. Self-efficacy and fatigue among healthcare workers during COVID-19 outbreak: a moderated mediation model of posttraumatic stress disorder symptoms and negative coping. Res Square. 2020. doi:10.21203/rs.3.rs-23066/v1

12. Hua C, Kai-yi Q, Yan-jun L. The relations between work-family conflict and job-related self-efficacy. J Guizhou Normal Univ. 2007. Available from http://en.cnki.com.cn/Article_en/CJFDTotalNATR200702011.htm.

13. Katz D, Kahn RL. The Social Psychology of Organizations. Vol. 2. New York: Wiley; 1978:528.

14. Lenaghan JA, Buda R, Eisner AB. An examination of the role of emotional intelligence in work and family conflict. J Manag Issues. 2007;19:76-94.

15. Mache S, Bernburg M, Vitzthum K, Groneberg DA, Klapp BF, Danzer G. Managing work-family conflict in the medical profession: working conditions and individual resources as related factors. $B M J$ Open. 2015;5(4):e006871. doi:10.1136/bmjopen-2014-006871

16. Malik M, Haider Z, Hussain A. Perceived emotional intelligence, work life balance and job satisfaction among healthcare professionals in Pakistan. Int J Pharma Res Allied Sci. 2019;8(2):80-86.

17. Mamidipalli S, Sree P, Supriya M. Mental health problems faced by healthcare workers due to the COVID-19 pandemic- A review. J Asian Psychiatr. 2020;51. doi:10.1016/j.ajp.2020.102119.

18. Naik KR. An investigation of emotional intelligence factors among health care professionals dealing with COVID 19 pandemic for effective relationship management by means of factor analysis; 2020. Available from: https://www.fergusson.edu/upload/document/ 51612_DrKasturiRNaik(NMITD).pdf. Accessed October 28, 2021.

19. Netemeyer RG, Boles JS, McMurrian R. Development and validation of work family conflict and family-work conflict scales. $J$ Appl Psychol. 1996;81:400-410. doi:10.1037/0021-9010.81.4.400

20. Wong CS, Law KS. Wong and law emotional intelligence scale. Leadersh Q. 2002. doi:10.1037/t07398-000

21. Schwarzer R, Jerusalem M. The general self-efficacy scale (GSE). Anxiety Stress Coping. 2010;12(1):329-345.

22. Huang H, Liu L, Yang S, Cui X, Zhang J, Wu H. Effects of job conditions, occupational stress, and emotional intelligence on chronic fatigue among Chinese nurses: a cross-sectional study. Psychol Res Behav Manag. 2019;12:351. doi:10.2147/PRBM.S207283 
23. Wu PE, Styra R, Gold WL. Mitigating the psychological effects of COVID-19 on health care workers. J CMAJ. 2020;192(17):E459-E460.

24. Rana W, Mukhtar S, Mukhtar S. Mental health of medical workers in Pakistan during the pandemic COVID-19 outbreak. Asian J Psychiatr. 2020;51:102080. doi:10.1016/j.ajp.2020.102080

25. Rastegar M, Memarpour S. The relationship between emotional intelligence and self-efficacy among Iranian EFL teachers. System. 2009;37(4):700-707. doi:10.1016/j.system.2009.09.013

26. Sergio R, Ormita P, Dungca AL, Gonzales JO. Emotional intelligence, work/family conflict, and work values among customer service representatives: basis for organizational support. J East Eur Cent Asian Res. 2015;2(1). doi:10.1554/jeecar.v2i1.86

27. Wang C, Pan R, Wan X, et al.Immediate psychological responses and associated factors during the initial stage of the 2019 Coronavirus disease (COVID-19) epidemic among the general population in China. Int J Environ Res Public Health. 2020;(17):1729.

28. Chirico F, Ferrari G, Nucera G, Szarpak L, Crescenzo P, Ilesanmi O. Prevalence of anxiety, depression, burnout syndrome, and mental health disorders among healthcare workers during the COVID-19 pandemic: a rapid umbrella review of systematic reviews. $J$ Health Soc Sci. 2021;6(2):209-220.

29. Chirico F, Ferrari G. Role of the workplace in implementing mental health interventions for high-risk groups among the working age population after the COVID-19 pandemic. J Health Soc Sci. $2021 ; 6: 145-150$.

30. Chirico F, Magnavita N. The crucial role of occupational health surveillance for health-care workers during the COVID-19 pandemic. Workplace Health Saf. 2020. doi:10.1177/2165079920950161
31. Magnavita N, Chirico F. New and emerging risk factors in occupational health. Appl Sci. 2020;10(24):1-7. doi:10.3390/app10248906

32. Yavas U, Babakus E, Karatepe OM. Attitudinal and behavioral consequences of work-family conflict and family-work conflict. Does gender matter? Int J Serv Ind Manag. 2008;19:7-31. doi:10.1108/ 09564230810855699

33. Jabeen S, Sheraz F, Haider S, et al. The nexus between global disruption due to the covid-19 and performance of the construction project. Manag Sci Lett. 2021;11(6):1871-1880. doi:10.5267/j. msl.2021.1.015

34. Ullah I, Ullah A, Ali S, et al. Public health expenditures and health outcomes in Pakistan: evidence from quantile autoregressive distributed lag model. Risk Manag Healthc Policy. 2021;14:3893. doi:10.2147/RMHP.S316844

35. Akbar A, Alam Rehman IU, Afridi FEA, Afridi FEA, Afridi FEA. Unraveling the dynamic nexus between trade liberalization, energy consumption, $\mathrm{CO} 2$ emissions, and health expenditure in Southeast Asian countries. Risk Manag Healthc Policy. 2020;13:1915. doi:10.2147/RMHP.S272801

36. Akbar M, Hussain A, Akbar A, Ullah I. The dynamic association between healthcare spending, $\mathrm{CO} 2$ emissions, and human development index in OECD countries: evidence from panel VAR model. Environ Dev Sustain. 2021;23(7):10470-10489. doi:10.1007/s10668020-01066-5
Psychology Research and Behavior Management

\section{Publish your work in this journal}

Psychology Research and Behavior Management is an international, peer-reviewed, open access journal focusing on the science of psychology and its application in behavior management to develop improved outcomes in the clinical, educational, sports and business arenas. Specific topics covered in the journal include: Neuroscience, memory and decision making; Behavior modification and management; Clinical

\section{Dovepress}

applications; Business and sports performance management; Social and developmental studies; Animal studies. The manuscript management system is completely online and includes a very quick and fair peer-review system, which is all easy to use. Visit http://www. dovepress.com/testimonials.php to read real quotes from published authors. 